\title{
Sensibilidade ecológica e ambientalismo: uma reflexão sobre as relações humanos-natureza
}

\section{Elenita Malta Pereira*}

\section{Resumo}

Neste artigo, são abordadas diferentes dimensões presentes nas representações humanas sobre a natureza: a sensibilidade ecológica, ou seja, a manifestação dos sentimentos e percepções humanas em relação ao mundo natural, e o ambientalismo, movimento construído historicamente, de caráter global, porém plurifacetado, disperso em diversas vertentes, que se dedica à proteção e conservação do ambiente natural e humano. O objetivo é analisar a historicidade dessas dimensões, considerando alguns de seus defensores e críticos. A discussão leva, finalmente, ao entendimento da relação dos humanos com a natureza como um problema tanto histórico quanto ético-moral.

Palavras-chave: Sensibilidade ecológica, História do ambientalismo, Ética ambiental, Ciências sociais e ambiente.

\footnotetext{
* Universidade Federal de Santa Catarina, Florianópolis, SC, Brasil.
} https://orcid.org/0000-0001-9835-391X. 


\section{Ecological sensitivity and environmentalism: a reflection on human-nature relationship}

\section{Abstract}

This paper discusses the differences between two dimensions present in human representations of nature: the ecological sensitivity, ie, human feelings and perceptions about nature; and environmentalism, a global movement built historically, which is multifaceted, scattered across various areas, and is dedicated to the protection and management of natural and human environment. The goal is to analyze the historicity of these dimensions, considering the views of some of its supporters and critics. The discussion, finally, enables to understand human relationship with nature as a problem that is both historical and ethical-moral.

Keywords: Ecological sensitivity, Environmentalism history, Environmental ethics, Social science and environment.

\section{Introdução}

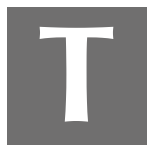

ornou-se comum, no período recente, que as pessoas se autodeclarem "ambientalistas", mesmo que não participem de um grupo da sociedade civil dedicado à proteção ambiental.

Será que muitas dessas pessoas são (ou querem parecer ser) ambientalistas ou estão expressando, na verdade, uma sensibilidade mais acurada em relação ao ambiente'?

Ao longo da história, as sociedades humanas construíram diferentes ideias, representações e práticas a respeito da natureza. Houve períodos em que foi enfatizada a necessidade de protegê-la, em outros, justificouse sua exploração intensiva. Entretanto, foi somente na década de 1970 que as Ciências Sociais passaram a levar em conta a dimensão ambiental em suas análises. No âmbito da Sociologia, Catton e Dunlap cunharam a

1 Uso aqui o termo "ambiente" no mesmo sentido de Almeida e Premebida (2014, p. 15): “(...) como o conjunto de meios naturais ou artificializados da ecosfera onde o ser humano se instalou, que ele explora e administra, e o conjunto dos meios não antropizados necessários à sua sobrevivência". 
expressão Sociologia Ambiental, em 1978, posteriormente dividida em três ramos de estudos: Modernização Ecológica, Desenvolvimento Sustentável e Sociedade de Risco (Lenzi, 2006). Na área da História, iniciativas de ensino e pesquisa em História Ambiental começaram a surgir nos anos 1970, protagonizadas por historiadores norte-americanos ${ }^{2}$ e europeus ${ }^{3}$.

Para compreender o surgimento da história ambiental como campo historiográfico específico, é preciso levar em consideração fatores sociológicos e epistemológicos. De acordo com José Augusto Pádua, foram tanto a emergência de movimentos ambientalistas em diversos países e a realização de conferências internacionais quanto as mudanças no mundo do conhecimento, consolidadas no século XX, sobre o "entendimento do mundo natural e de seu lugar na vida humana" (Pádua, 2010, p. 81), que instigaram o interesse dos historiadores pelas relações entre seres humanos e natureza. Especialmente importante foi o conceito de ecossistema ${ }^{4}$, que obrigou os cientistas a repensarem a posição dos humanos na história e na Terra.

A emergência de movimentos ambientalistas nos anos 1960 também foi importante no contexto de surgimento da Sociologia Ambiental. Em especial, a realização do primeiro Earth Day, em 1970, nos Estados Unidos, mas também a publicação do Relatório Meadows, e a conferência da ONU em Estocolmo (ambos em 1972), foram eventos que mostraram a necessidade de contribuição da Sociologia para um maior entendimento

${ }^{2}$ Nos Estados Unidos, o primeiro curso universitário com o título de "História Ambiental" ocorreu em 1972, na Universidade da Califórnia, em Santa Bárbara, ministrado pelo historiador cultural Roderick Nash. A primeira sociedade científica na área foi a American Society for Environmental History (ASEH), criada em 1977.

${ }^{3} \mathrm{Na}$ França, é importante mencionar a revista Annales, que publicou um número especial sobre história e ambiente, em 1974. Na apresentação deste número, o editor, Emmanuel Le Roy Ladurie "fez questão de afirmar que não estava cedendo aos imperativos de uma moda, pois desde longo tempo a revista havia escolhido se interessar pelos temas de uma história ecológica" (Pádua, 2010, p. 82).

4 Para Worster (2003, p. 28-29), "deve-se definir um ecossistema como uma entidade coletiva de plantas e animais que interagem uns com os outros e com o ambiente não vivente (abiótico) num dado lugar [...] um ecossistema é um subgrupo da economia global da natureza - um sistema local ou regional de plantas e animais que trabalham em conjunto para criar os meios de sobrevivência". 
dos desafios ambientais e para uma reflexão sobre o próprio ambientalismo ${ }^{5}$ (Almeida; Premebida, 2014, p. 23-24).

No caso da História Ambiental, ela trata, em linhas gerais, "do papel e do lugar da natureza na vida humana" (Worster, 1991, p. 201) e se caracteriza pela ênfase nas interações recíprocas entre sociedades e natureza, por meio de mecanismos de coevolução. José Augusto Drumonnd destaca a importância de colocar a natureza na história: uma mudança de paradigma nas ciências sociais. A natureza se torna agente de transformação dos seres humanos, com "a capacidade de condicionar significativamente a sociedade e a cultura humanas" (Drummond, 1991, p. 180). De acordo com sua interpretação, isso significa que o cientista social credita às "forças da natureza" o caráter de agente modificador e condicionador de cultura, como uma mudança relevante na maneira de pensar e estudar processos sociais. Não somente a humanidade interfere e modifica a paisagem; esta também tem o poder de atuar sobre os humanos, condicionando a cultura local.

Esse campo das Ciências Sociais está intimamente ligado às preocupações das últimas décadas sobre o ambiente. Trata-se também de um contexto imerso em considerações de ordem ética. O desenvolvimento técnico e científico concedeu ao ser humano um poder de destruição do meio natural nunca antes possível. Isso trouxe à tona uma reflexão ética sobre a responsabilidade humana em relação ao ambiente que seria deixado para as gerações humanas (Jonas, 2006).

\footnotetext{
${ }^{5} \mathrm{O}$ artigo não tem por objetivo discutir o conceito de ambientalismo e suas variações. $\mathrm{O}$ termo aqui é usado no seu sentido amplo, mas estou ciente de seu caráter extremamente plural e das várias possibilidades de classificação/divisão. Jatobá, Cidade e Vargas (2009, p. 32-33) dividem o ambientalismo em três correntes ou abordagens: a da "ecologia radical", ou ecologismo, partindo de uma visão "romantizada da natureza, sem permissão de nenhum uso antrópico, mas apresenta também a proposta do biorregionalismo, que prega uma peculiar forma de interação dos humanos com a natureza. A abordagem do ambientalismo moderado propõe a conciliação dos usos antrópico e conservacionista em um mesmo território sem, no entanto, esclarecer como atingir esse objetivo. A abordagem da ecologia política vê o território como palco de conflitos socioambientais que refletem não apenas o modelo cultural e econômico vigente, mas também a correlação de forças preponderante na sociedade".
} 
Diante do exposto, as posturas éticas, bem como as ideias, representações e sensibilidades humanas em relação ao ambiente tornam-se objetos privilegiados de estudo pelo pesquisador em Ciências Sociais. Neste artigo, apoiado no diálogo proposto entre autores e autoras de diferentes áreas das Ciências Sociais, meu objetivo é abordar duas diferentes dimensões presentes nas representações humanas sobre a natureza: a sensibilidade ecológica, ou seja, como os humanos se sensibilizam em relação à natureza e como se percebem nela, e o ambientalismo, este um movimento construído historicamente, de caráter global, porém multifacetado, disperso em diversas vertentes, que se dedica à proteção e conservação ${ }^{6}$ do ambiente.

Para atender ao proposto, o artigo está dividido em quatro partes, excetuando a presente seção e as considerações finais. Na primeira e na segunda partes, construo uma breve historicização da sensibilidade ambiental e do ambientalismo. A seguir, abordo as críticas e limitações dos movimentos ambientalistas. Na quarta parte, argumento sobre a importância e a validade, ainda, da discussão sobre ética ambiental, como proposta para romper a disjunção sociedade-natureza.

\section{Sensibilidade ecológica: um breve histórico}

A atual representação dominante na maioria das sociedades é a de ruptura entre humanidade e natureza. Vários autores tentaram explicar a causa dessa ruptura, mas um texto considerado referência no assunto foi publicado na revista Science, em 1967, pelo historiador norte-americano Lynn White. Nesse artigo, White defende que a causa profunda da crise ecológica contemporânea está enraizada na herança judaico-cristã,

\footnotetext{
${ }^{6}$ A ideia de conservação surge nos Estados Unidos, onde desde o século XIX havia o debate entre "conservacionistas" e "preservacionistas". "Os primeiros se preocupavam, sobretudo, com a racionalidade na utilização dos recursos naturais, enquanto os outros defendiam a natureza com os argumentos da fruição estética e da transcendência espiritual proporcionada pelos aspectos sublimes da natureza selvagem" (Franco; Drummond, 2009, p. 46). Em termos práticos, os "conservacionistas" propunham o uso dos elementos naturais com responsabilidade para as gerações futuras; já os preservacionistas sugeriam a reserva de áreas - de preferência as mais belas - para a constituição de parques naturais sem a presença humana.
} 
componente importante na formação da cultura. O grande problema dessa herança seriam seus "ensinamentos" a respeito do ambiente:

o cristianismo herdou do judaísmo o conceito de tempo linear e uma surpreendente história da criação. Deus criou todas as plantas, animais etc. e o homem. Deus planejou tudo explicitamente para uso e benefício do homem. [...] ainda que o corpo do homem seja feito de argila, ele não é simplesmente parte da natureza, é feito à imagem e semelhança de Deus. Nos padrões ocidentais, é o cristianismo a religião mais antropocêntrica que o mundo já viu. O cristianismo estabeleceu que é do desejo de Deus que o homem explore a natureza para suas necessidades (White, 1981, p. 16).

Segundo White, a ciência e a tecnologia estariam impregnadas da ideologia do progresso, fruto do pensamento judaico-cristão. Como o problema era religioso, o autor sugeria uma solução também religiosa: "o senso herético e profundamente religioso dos Franciscanos primitivos da autonomia espiritual de todos os componentes da natureza pode e deve indicar uma direção. Eu proponho São Francisco de Assis como patrono dos ecologistas" (White, 1981, p. 22).

$\mathrm{O}$ artigo de White sofreu várias críticas ${ }^{7}$, no entanto, segundo Keith Thomas (1988, p. 28), tornou-se "quase que uma bíblia para os ecologistas de nossos dias". Em contraponto à tese de White, Thomas argumenta que,

como notaria Karl Marx, não foi sua religião, mas o surgimento da propriedade privada e da economia monetária o que conduziu os cristãos a explorar o mundo natural de uma forma que os judeus nunca fizeram; foi aquilo que chamou 'a grande influência civilizadora do capital' que, finalmente, pôs fim à 'deificação da natureza' (Thomas, 1988, p. 29).

Claude Raynaut (2006, p. 1) reconhece o mérito do artigo de White, por ter trazido para o debate público a centralidade que a dicotomia humanos/natureza desempenha no sistema de pensamento ocidental, no

${ }^{7}$ Para uma boa análise dessas críticas, consultar Pepper (1996, p. 197-202). Antes de White, filósofos e teólogos já haviam denunciado o judaísmo e o cristianismo como fontes dos maus tratos aos animais, entre eles, Arthur Schopenhauer, Wilfrid Scawen Blunt e Hastings Rashdall (Thomas, 1988, p. 28). 
entanto, considera sua argumentação muito simplificadora. Para Raynaut, a ruptura entre ser humano e natureza foi construída historicamente, desde a Antiguidade, por diferentes povos, de forma não linear e muito complexa, não apenas pela influência judaico-cristã, como afirmou o historiador norte-americano.

Desde a antiguidade grega, houve períodos de avanço e recuo, em direção a uma maior sensibilidade humana em relação à natureza. Raynaut cita uma série de significações de natureza que vão mudando com o tempo. Por exemplo, na antiguidade grega, a representação dominante percebia a natureza como uma totalidade, holística, que possuía alma, a "Alma do Mundo", ideia presente em "praticamente todos os pensadores da antiguidade" (Raynaut, 2006, p. 3). No Renascimento (séculos XIV a $\mathrm{XV}$ ), houve o início de uma ruptura mais forte, devido a três fatores: o retorno ao pensamento grego; a perspectiva linear - o humano como observador do mundo; e o surgimento da ideia de "sujeito". Na Revolução Científica (séc. XVI/XVIII), consolidou-se a observação da natureza. O princípio formulado por Descartes do mundo como máquina, separado do humano - ser pensante, possuidor e dono do mundo - passou a dominar as representações.

A partir do século XVIII, duas diferentes visões da natureza começam a ser construídas. A primeira delas tem origem com o naturalista inglês Gilbert White, que chegou a uma concepção de harmonia arcadiana no mundo natural. Segundo Worster (2011), essa concepção é a matriz do vitalismo e de visões orgânicas, holísticas da natureza, uma tradição de pensamento que seria seguida por Henry Thoreau, John Muir, Aldo Leopold e Rachel Carson, entre outros. A outra visão é tributária da obra do naturalista sueco Carl Linnaeus que, num sentido oposto a White, poderia ser tomado, de acordo com Worster (2011), como representante de uma "visão imperial" na natureza. Para o historiador, o modelo de Linnaeus tinha muito mais a dizer sobre a missão humana de explorar do que de conservar. Ao ampliar o conhecimento sobre os elementos naturais, Linnaeus acabou colaborando com a tradição imperial que, 
cada vez mais, encarou a natureza como recurso, subserviente às razões e necessidades humanas (Worster, 2011, p. 53).

Já no século XIX, o movimento romântico preconizava uma volta à natureza, onde a humanidade poderia encontrar harmonia, êxtase e felicidade. Segundo Pádua (2005, p. 62), "um dos aspectos mais centrais e inclusivos daquele movimento intelectual foi justamente a valorização do mundo natural, seja em termos estéticos, espirituais ou éticos". Jean-Jacques Rousseau, um dos precursores do romantismo, defendia a importância da natureza livre e selvagem. Para ele, a humanidade era culpada da degeneração da natureza.

A herança do romantismo levou ao surgimento das correntes mais radicais de valorização e defesa da natureza, tanto nos países de cultura alemã quanto anglo-saxônica. Foi nos Estados Unidos que essa ideia encontrou espaço para se materializar. De acordo com o sociólogo Edgar Morin (1997, p. 55), os motivos para isso eram muito evidentes: a percepção da América como um continente selvagem, "constituído de extensões sem limites e de desertos". Nesse país, que ainda possuía grandes áreas de florestas - ao contrário da Europa -, foi criada a primeira reserva natural do mundo, o Parque Nacional de Yellowstone, em 1872. Na sequência, surgiram mais três Parques Nacionais: das Sequóias, Yosemite e General Grant (hoje Kings Canyon), todos em 1890, e muitos outros ao longo do século XX. O modelo da wilderness se transformou em realidade física nos primeiros parques naturais do mundo, lugares em que a natureza seria reservada para que pudesse se preservar intacta.

Esse movimento atingiu também o Brasil, onde "a necessidade de proteger testemunhos da natureza intocada expressou-se muito cedo dentro de certos meios intelectuais" (Raynaut, 2006, p. 25). Pesquisas na área de história ambiental, como as de Pádua (2002), averiguaram indícios de crítica ambiental no Brasil já no século XVIII. Não era uma crítica à modernidade e aos males do desenvolvimento como se formula atualmente, mas uma denúncia da "realidade brasileira como uma espécie de farsa do avanço 
civilizatório, uma ordem calcada em instituições e técnicas herdadas do atraso colonial" (Pádua, 2002, p. 10).

Bublitz (2006) analisou o projeto de desenvolvimento para o Brasil, formulado por José Bonifácio de Andrada e Silva no século XIX, que, entre outros fatores,

propunha o fim da escravidão já em 1823, defendia um projeto social para a inclusão sistemática de índios e de negros na sociedade, sugeria a reforma agrária, incentivava a valorização das potencialidades nacionais, o uso racional do meio ambiente e a importância da efetivação de laços de cooperação, de confiabilidade e de patriotismo no Brasil (Bublitz, 2006, p. 16).

Podemos citar também os trabalhos de Dean (1997), Franco e Drummond (2009), Duarte (2010), Pereira (2013), como pesquisas que se dedicaram a analisar essa crítica ambiental brasileira dos séculos XIX e XX, entre outras. Esses trabalhos revelam que havia uma sensibilidade que motivava a crítica à devastação dos elementos naturais, no entanto, eram posições marginais, sem poder de interferir na postura hegemônica adotada desde a colonização portuguesa.

\section{Ambientalismo}

A difusão do ambientalismo - uma das representações sobre a relação entre humanos e natureza possíveis - é chamada por McCormick como "revolução ambientalista", uma das mais importantes revoluções conceituais do século XX. Já Morin entende esse fenômeno como resultado do encontro entre a ciência ecológica e o movimento neonaturista. Defender a natureza não eram mais "coisas simplesmente irracionais, infantis, femininas. Ao contrário, a preocupação com a defesa da natureza torna-se uma atitude prudentemente racional" (Morin, 1997, p. 56).

McCormick se propõe a buscar as raízes do ambientalismo, e as encontra nos Estados Unidos, no Reino Unido e nas colônias inglesas. Segundo o autor, "os primeiros grupos protecionistas foram criados na Grã-Bretanha na década de 1860" (McCormick, 1992, p. 15). Já nos 
Estados Unidos, os grupos surgiram no final do século XIX, divididos no foco de sua argumentação. Enquanto alguns defendiam a reserva de áreas "virgens", sem a presença humana, ou seja, a preservação da natureza, outros queriam garantir a exploração dos "recursos naturais" de modo racional e sustentável, numa perspectiva conservacionista.

McCormick explica o surgimento do ambientalismo na Inglaterra através das descobertas científicas, durante os séculos XVI, XVII e XVIII. Nesse período histórico, foram estabelecidos os fundamentos da botânica e da zoologia modernas por uma sucessão de naturalistas. Essas pesquisas afetaram a visão do humano quanto ao seu lugar na natureza. A seguir, no século XIX, o trabalho de Darwin ajudou a reforçar a ideia de que a humanidade fazia parte da natureza, e, com isso, começou a firmar-se uma consciência biocêntrica, que vai se manifestar plenamente na segunda metade do século $X X$, na emergência de movimentos ambientalistas em todo o mundo ${ }^{8}$.

Já nos Estados Unidos, o despertar para o ambientalismo foi motivado pela devastação das florestas e pelos escritos de Alexander Wilson, John James Audubon, Ralph Waldo Emerson e Henry David Thoreau, entre outros autores (McCormick, 1992, p. 29). O trabalho de Thoreau foi especialmente importante, ao perceber os elementos da natureza de forma holística, interligada. Thoreau formulou reflexões sobre a preservação da natureza, a partir de sua experiência pessoal, ao passar dois anos vivendo isolado numa cabana junto ao Lago Walden, em Concord, Massachusetts. Ele se tornou um naturalista autodidata, e, em seus escritos, construiu uma crítica cortante "dos padrões e das aspirações da sociedade industrial" (Pepper, 1996, p. 254). Muito influenciado pela obra de Alexander von Humboldt, enfatizou a interdependência entre as comunidades vegetal, animal e humana, numa visão holística, oferecendo assim uma perspectiva ecológica sobre seu microcosmo

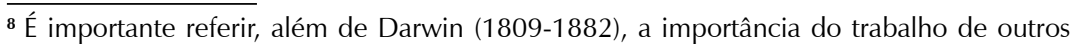
naturalistas, como os alemães Alexander von Humboldt (1769-1859) e Ernst Haeckel (18341919). Enquanto Humboldt foi inspiração para Darwin, como cientista polivalente e como viajante científico pelo "Novo Mundo", cujos passos seriam seguidos pelo inglês, Haeckel foi discípulo e divulgador da obra de Darwin, que o influenciou na formulação do termo Ecologia (Worster, 2011). 
em Concord (Worster, 2011, p. 65). Para Thoreau, a terra que pisamos não é morta, mas possui um corpo, um espírito, criado por Deus. Ele defendia que os seres da natureza tinham direito de existir, independentemente dos humanos. Thoreau tornou-se um "herói ambiental" a partir dos anos 1960, quando seus textos foram redescobertos (Nash, 1989).

No final do século XIX, os grupos protecionistas se dividiram em preservacionistas e conservacionistas. Os protagonistas desse debate foram John Muir e Clifford Pinchot:

enquanto Muir e os preservacionistas falavam em "proteger" ou "preservar" o meio ambiente, o que frequentemente implicava a total exclusão das áreas virgens de qualquer alternativa que não fosse recreação, outros [liderados por Pinchot] falavam de "conservação", ou de exploração sustentada de recursos tais como solo, florestas e águas (McCormick, 1992, p. 31).

Muir foi decisivo na criação de Yosemite e ajudou a fundar o Sierra Club, em 1892, organização que se tornou um centro de aglutinação da causa preservacionista. Sua defesa das áreas virgens era baseada mais em emoção do que em racionalidade, utilizando termos religiosos. Para Nash (1989, p. 41), a natureza era a igreja de Muir, o lugar onde adorava a Deus, a proteção da natureza tornando-se uma espécie de guerra santa.

Já Pinchot envolveu-se, primeiramente, com a proteção das florestas. Influenciado por técnicas de manejo florestal alemãs, Pinchot argumentava que as florestas não deviam ser fechadas à ocupação do público, mas sim gerenciadas para contribuir na economia do país. A defesa da natureza era pautada por um utilitarismo confesso. Além das florestas, também a água era um precioso recurso para os conservacionistas. Os rios deviam ser protegidos pela sua importância para o transporte, para o consumo doméstico e comercial de água, para o controle das cheias e erosão, e para o fornecimento de energia elétrica (McCormick, 1992, p. 32).

Além do Sierra Club, nos Estados Unidos, é importante citar também a Audubon Society, entidade de orientação conservacionista, criada em 1905, em Nova lorque, a partir de um movimento contra a caça de pássaros 
(Nash, 1989). Seu nome homenageia o ornitólogo franco-americano John James Audubon, autor de The birds of America (1827-1838).

Figura importante para o ambientalismo norte-americano, Aldo Leopold defendeu a "ética da terra", segundo a qual os seres humanos não deveriam se propor conquistadores da "terra-comunidade", mas membros e cidadãos dela. Para Leopold, todas as espécies fazem parte de um organismo complexo: a Terra. Ele queria transcender o antropocentrismo com sua premissa ética ${ }^{9}$, propondo que a humanidade pensasse como uma montanha (Nash, 1989, p. 65). Isso significava pensar, no contexto em que Leopold vivia, que a caça de lobos levaria à supressão da cobertura vegetal de uma montanha, já que os lobos eram predadores dos veados; estes, sem o seu predador, iriam multiplicar-se numa taxa maior e demandariam mais alimento - a cobertura vegetal. Só assim, em sua visão, seria possível compreender a interligação entre os seres e que o planeta em sua totalidade é vivo. As concepções de Leopold influenciaram o surgimento do moderno ambientalismo nos anos 1960, por sua percepção holística e biocêntrica.

John McNeill (2000, p. 338) considera que o movimento ambientalista nos Estados Unidos tem uma "progenitora", a bióloga Rachel Carson, autora de Primavera Silenciosa, o primeiro alerta mundial sobre os perigos dos agrotóxicos. Carson foi apontada como uma das 25 mulheres mais poderosas do século XX pela revista Time (2010). Ela já era uma bióloga marinha famosa em seu país, pois sua trilogia sobre o mar foi muito bem recebida nos anos 1940-50 ${ }^{10}$. Em 1958, começou a escrita de Primavera Silenciosa, a partir de inúmeras denúncias de problemas com aplicações de DDT. A primeira versão de Primavera Silenciosa foi publicada, em fascículos, em junho de 1962, na revista New Yorker. Em setembro do mesmo ano, foi lançado o livro. A autora sofreu uma enxurrada de críticas preconceituosas, pelo fato de ser mulher e por estar tratando de um tema dominado pela poderosa indústria química.

9 Em "Pensar como uma montanha: a Sand County almanac", Leopold (2008, p. 206) defendeu que "uma coisa é certa quando tende para preservar a integridade, a estabilidade e a beleza da comunidade biótica. É errada quando tendo o sentido oposto".

10 Livros de Rachel Carson: Sob o mar-vento ([1941] 2011), O mar que nos cerca ([1951] 2010) e Beira-mar ([1955] 2010). 
Na obra, utilizando linguagem acessível e apaixonada, Carson demonstrou que o DDT penetra na cadeia alimentar e chega em todos os seres vivos; as aplicações da substância não matavam apenas as "pragas" às quais se dirigiam, mas também muitas outras espécies; a autora denunciou a contaminação das águas em geral e a demora para degradar-se no ambiente. Ao criticar o uso dos agrotóxicos, Carson tratava de um tema fundamental: a relação das pessoas com a natureza. Ao examinar a legitimidade do que chamava "cadeias de envenenamento", a autora levantou uma importante questão ética: "quem foi que decidiu - quem é que tem o direito de decidir - em nome de incontáveis legiões de pessoas que não são consultadas - que o valor supremo é um mundo sem insetos, ainda que venha a ser um mundo estéril, destituído da graça decorativa de uma asa encurvada, de um pássaro em voo?" (Carson, 1964 , p. 137). A primavera silenciosa, sem o canto dos pássaros, sem o rumor da vida, era o que a bióloga queria evitar com o alerta presente em seu livro.

A década de 1970 pode ser considerada o boom do ambientalismo, ou "a era da ecologia", segundo Worster (2011), pois é quando este conceito transpõe a academia e torna-se de uso popular (Acot, 1990). Um dos eventos mais marcantes nesse contexto foi o primeiro Earth Day, em abril de 1970, que contou com as palestras de Barry Commoner, Paul Ehrlich, René Dubois, Ralph Nader, Benjamin Spock, e mesmo do poeta beat Allen Ginsberg (Worster, 2011, p. 357), personagens que se tornariam referências para os movimentos ambientalistas que começavam a surgir em todo o mundo. Na década de 1970, foram criadas importantes entidades, como o Friends of the Earth International (1971), o Geenpeace, no Canadá (1971), a Sea Shepherd Conservation Society, nos EUA (1977), entre muitas outras.

No Brasil, que vivia o período de maior repressão de uma ditadura civil-militar, nessa mesma época surgiu a Associação Gaúcha de Proteção ao Ambiente Natural (AGAPAN), em abril de 1971, em Porto Alegre-RS. Liderada pelo engenheiro agrônomo José Lutzenberger e o advogado Augusto Carneiro, e contando com cerca de 30 membros fundadores, a AGAPAN se envolveu em diversas lutas. No âmbito local (Porto Alegre e Rio Grande do Sul), durante os anos 1970, foram exemplos o combate à poda incorreta e ao 
corte de árvores; a luta contra a poluição do ar e das águas, cuja expressão máxima foi a luta contra a Celulose Borregaard; a denúncia da mortandade de mariscos, peixes e outros animais na praia de Hermenegildo-RS, em 1978, como um desastre provocado por vazamento de agrotóxicos no mar, contra a versão oficial dos representantes da ditadura, de que teria ocorrido um fenômeno natural, conhecido como Maré Vermelha. A entidade se envolveu em campanhas mais abrangentes, como o combate ao uso de agrotóxicos, a defesa da floresta Amazônica, e a divulgação da necessidade de uma nova ética nas relações entre humanos e natureza, de cunho não antropocêntrico ${ }^{11}$.

Em geral, esses grupos ambientalistas veiculavam mensagens de teor catastrofista, bastante pessimistas, especialmente nos anos 1970. Fabiano Rückert (2015, p. 13-14) chama a atenção para a contribuição do sociólogo Enrique Leff, com seu conceito de racionalidade ambiental, como um dos "intelectuais que acreditam na possibilidade de a crise ambiental produzir respostas positivas nos diferentes segmentos da realidade social". Por meio desse conceito, Leff

explorou as diferenças entre a concepção de natureza existente na racionalidade capitalista (baseada nos dogmas da ciência e na supervalorização do mercado) e o surgimento de uma racionalidade alternativa - uma racionalidade ambiental - marcada por novas formas de significação cultural da natureza, por novos hábitos de consumo e pela busca de tecnologias com baixo impacto ambiental (Rückert, 2015, p. 13).

Carlos Walter Porto-Gonçalves (2009) chama a atenção para a contribuição de uma epistemologia crítica que Enrique Leff vem desenvolvendo desde 1975, destacando, entre seus livros, Ecologia e Capital. Sua obra seria um contraponto às considerações simplistas de alguns ambientalistas, "mostrando a pobreza da ideia que atribui a degradação ambiental à ação antrópica, como se o homem que age junto ao meio o fizesse enquanto ser estritamente

11 Para o surgimento da AGAPAN, consultar Pereira (2019, no prelo). Para um histórico do movimento ambientalista no Rio Grande do Sul, consultar Bones e Hasse (2002), Oliveira (2005), Pereira (2018). 
biológico e não por meio da complexidade social, cultural e através de relações de poder" (Porto-Gonçalves, 2009, p. 86).

\section{Crítica ao ambientalismo}

Diferente da percepção extremamente positiva de McCormick sobre a internacionalização das preocupações com a natureza, Alphandéry, Bitoun e Dupont (1992) apresentam uma visão bastante crítica a respeito desse fenômeno. Para os autores, a ecologia como movimento político teria falhado. Apesar de toda a badalação em torno do assunto, a ecologia não teria conseguido afirmar-se como um novo paradigma da cultura, à altura da crise moral e política planetária. Haveria também o perigo de a ecologia voltar-se para nacionalismos autoritários, xenofobia, racismo. No entanto, ainda valeria a pena examinar a via que contesta o lugar do mercado e da tecnociência, refletindo sobre a definição das necessidades e a relação com a terra (Alphandéry, Bitoun, Dupont, 1992, p. 11).

O boom da ecologia teria levado ao medo ecológico, um medo planetário: é a Terra toda que está ameaçada pelas chuvas ácidas, buraco na camada de ozônio e efeito estufa. Porém, o maior dos medos era o da bomba atômica, num mundo dividido pela Guerra Fria, após a Segunda Guerra Mundial. Pairava no ar o risco de uma terceira guerra ou de vazamentos em usinas nucleares. Para Worster (2011), a era da ecologia começou com a explosão da primeira bomba atômica, no deserto do Novo México, em 16 de julho de 1945. Pela primeira vez, havia uma força tecnológica que parecia capaz de destruir a vida no planeta; era a concretização do sonho de Bacon, do império humano sobre a natureza, o que Worster (2011, p. 343) interpreta como "o lado negro do legado do lluminismo". Foi a partir da ameaça da bomba atômica que uma nova consciência moral teria tomado forma, o ambientalismo.

Além da questão nuclear, no entanto, havia outras ameaças. Como vimos acima, nos anos 1960, Rachel Carson denunciou os perigos dos agrotóxicos em nossa alimentação e para os ecossistemas em que eram 
aplicados. Havia também a ameaça da explosão populacional, expressa no best seller "The Population bomb" (Ehrlich, 1975), e do sistema capitalista como um todo, denunciada pelo biólogo e ecologista Barry Commoner, entre outros. Arruda, Silva e Biasetto (2011, p. 51) afirmam que, nesse contexto, "o que efetivamente o ambientalismo acrescentou às ideias sobre os limites, concepções e alterações provocadas pelos homens no meio ambiente foi o senso de urgência, que chegava aos limites do apocalipse".

Nos anos 1970, uma série de livros, artigos e manifestos foram publicados por autores que se apresentaram como "profetas do apocalipse" global. Podem-se citar, como exemplos, "Antes que a natureza morra", de Jean Dorst (1973); "Morte e sobrevivência da Terra" (1972), de Richard Falk; "A utopia ou a morte" (1973) e "O crescimento da fome" (1974), de René Dumont; "Fim do futuro? Manifesto ecológico brasileiro", de José Lutzenberger ([1976] 1983), entre outras obras de cunho catastrofista.

Para o sociólogo Edgar Morin, as profecias catastrofistas fizeram parte do primeiro estágio do desenvolvimento do movimento ambientalista. $\mathrm{O}$ relatório do Clube de Roma, publicado no formato livro sob o título "Limites do Crescimento" (Meadows et al., 1972), foi um dos mais importantes documentos de cunho ecológico desse período histórico, "prevenia o mundo inteiro de que a continuação do crescimento econômico e industrial, no mesmo ritmo e segundo as mesmas modalidades do passado, arrastaria o conjunto da biosfera e consequentemente toda a humanidade para a catástrofe" (Morin, 1997, p. 56).

Outro manifesto importante, inspirado no relatório do Clube de Roma, "A blueprint for survival", foi preparado pelo ecólogo britânico Edward Goldsmith, editor da revista The Ecologist, juntamente com Robert Allen, Michael Allaby, Davoll John e Lawrence Sam e foi endossado por 35 personalidades científicas de renome mundial. A primeira versão foi publicada em janeiro de 1972, ocupando toda a edição de The Ecologist (v. 2, n.1). Em 14 de setembro, o manifesto foi republicado em livro pela editora Penguin Books (Goldsmith et al., 1972). 
Segundo Alphandéry, Bitoun e Dupont (1992, p. 18-19), o momento de glória da ecologia na França, ao longo dos anos 1970, foi provocado "pela contestação do modo de vida industrial, a reação às poluições, as profecias do Clube de Roma a respeito do esgotamento próximo dos recursos naturais, a crise do petróleo e o movimento antinuclear". Na época, essas contestações não foram levadas muito a sério; a ecologia foi encarada como mais um modismo passageiro e idealista. Entretanto, nos anos 1980, a situação foi mudando entre políticos, empresários e população em geral: "todo mundo, ou quase, se pretende ecologista" (Alphandéry, Bitoun, Dupont, 1992, p. 19).

Alphandéry Bitoun e Dupont explanam sobre os principais componentes dessa sensibilidade ecológica que conquista cada vez mais adeptos. Além do medo ecológico, a reação aos "estragos do progresso" é uma dimensão fundamental. Ideias básicas da ecologia passaram a guiar as atitudes de muitas pessoas nos países ricos, o que levou à reabilitação das teses de Ivan Illich sobre as relações entre os humanos modernos e as máquinas (suas análises abrangem a escola, transportes, energia, técnica e industrialização). As ideias de Illich a respeito do transporte, especialmente, tornaram-se espantosamente atuais. Segundo ele, o sistema de transportes aumentava as desigualdades sociais: "o desenvolvimento dos transportes reduz a igualdade entre os homens, limita a mobilidade pessoal dentro de um sistema de rotas traçadas a serviço das indústrias e das burocracias [...]. As pessoas se convertem em prisioneiras do veículo que as leva da casa para o trabalho" (Illich, 1985, p. 24). Para o autor, as desigualdades aumentariam na medida em que "poucos podem fazer deslocamentos longos, o que Ihes dá prestígio social, enquanto a maioria tem que se deslocar com mais rapidez pelos mesmos trajetos monótonos e passam cada vez mais tempo nesses deslocamentos" (Illich, 1985, p. 24).

Alphandéry, Bitoun e Dupont (1992) acreditam que, ao longo dos anos 1980, ganha força a ideia de que a indústria deve adequar-se à ecologia, para não perder seus clientes - agora preocupados com o meio ambiente - e mesmo para aumentar seus lucros. Começa a surgir o que, no século $\mathrm{XXI}$, seria chamado de "economia verde": alimentos biológicos, produtos 
ecológicos, marketing verde para vender mais. Não se defende a mudança na lógica do crescimento ilimitado, muito pelo contrário. A ecologia passa a ser vista como o futuro da economia, e até mesmo do sistema capitalista.

Outra dimensão dessa sensibilidade ecológica construída a partir dos anos 1970 é a que evoca a Natureza pela ausência, já que os cenários para o futuro são muito pessimistas. Os elementos necessários à vida poderiam vir a faltar, pois a humanidade teria interferido no ambiente muito além do que seria considerado sensato. Essa sensibilidade ecológica atual também exprimiria "um mal-estar profundo nas sociedades em que se acumulam mercadorias e resíduos enquanto se artificializam as relações do homem com o ambiente" (Alphandéry, Bitoun, Dupont, 1992, p. 26). Não é só a vida humana que pode estar ameaçada, diante da hipótese do desaparecimento dos ecossistemas, mas também o encantamento que a natureza traz à humanidade.

A partir dessa sensibilidade ecológica, os autores identificam dois discursos sobre o ambiente. O primeiro, quantificador, liga-se à salvaguarda dos ecossistemas e dos grandes equilíbrios planetários. Já o segundo retoma a ideia de que a felicidade humana não está apenas na acumulação de mercadorias, mas também nas alegrias estéticas e numa relação mais direta com a natureza. Certamente, o primeiro discurso tem levado larga vantagem sobre o segundo. O conceito dominante de "desenvolvimento sustentável" expressa bem a ideia de que a Natureza é formada de "recursos" a serem dominados e explorados "com responsabilidade" para o bem da humanidade (atual e gerações futuras).

A hipótese Gaia, de James Lovelock e Lynn Margulis, ao defender que a Terra é um ser vivo - como intuía Aldo Leopold nos anos 1940 -, veio reforçar essa sensibilidade ecológica pela via do medo. Gaia, nome grego da antiga deusa-mãe Terra, é hoje a biosfera como sistema autorregulado extremamente complexo, que se tornou argumento científico para reatualizar o ideal de unidade da humanidade. Gaia é, "em todos os níveis, um sistema vivo homeostático, em constante evolução" (Morin, 1997, p. 60). Porém, essa constatação impõe deveres à humanidade. Se alterar esse sistema, corre risco de destruir a si própria e a vida na Terra. Essa ameaça foi decisiva 
para elevar a ecologia ao patamar global, planetário. A imagem da Terra vista do espaço foi símbolo emblemático que contribuiu fortemente para consolidar essa representação.

Entre os muitos componentes da sensibilidade ecológica - por isso Alphandéry, Bitoun e Dupont (1992, p. 34) Ihe atribuem um caráter sincrético - um dos mais importantes é a dimensão moral. Os autores citam os exemplos de Jacques Cousteau e René Dumont. Cousteau, com seu discurso pedagógico, tornou-se popular com seus vídeos filmados nos oceanos. Sua "bandeira" maior era ensinar as pessoas a amar a natureza, para despertar a vontade de protegê-la. Enquanto Cousteau não expunha suas posições políticas, Dumont não hesitava em assumir sua oposição ao liberalismo e seu papel de anunciador de catástrofes. Dumont era engenheiro agrônomo, professor, foi candidato à presidência da França, defendendo a ecologia. Escreveu o livro "A utopia ou a morte" (Dumont, 1973), um manifesto ecológico em formato de profecia, no qual denuncia o consumismo, a destruição dos elementos naturais até a exaustão, seguindo o modelo norte-americano e europeu de consumo, para gerar mais empregos, mais crescimento, numa lógica absurda e destrutiva. E esse quadro se agravava com a explosão demográfica, sem controle, sem planejamento, principalmente entre a população pobre.

Alphandéry, Bitoun e Dupont (1992, p. 38) constatam que a busca de identidade nas sociedades ocidentais levou à "necessidade de natureza", a partir dos anos 1970. Individualismo e proteção à natureza poderiam andar juntos, na procura de identidade e de comunicação. A natureza é percebida como um recurso para a estética pessoal e cultura do eu, ou seja, estar em paz com o ambiente é bom para o indivíduo.

Essa cultura naturalista, que contribuiu para a valorização do local, das raízes e das redes, difundiu também conselhos para um consumo mais saudável. O que poderia parecer contraditório - aliar consumo e natureza - tornou-se um eficiente motor de vendas para o capitalismo. O incentivo à prática de hobbies na natureza, como turismo ecológico, caminhadas, ciclismo etc., tem como consequência, muitas vezes, enormes gastos. É 
uma espécie de ecologia do consumo. Além disso, pipocam por toda a parte lojas especializadas em alimentação saudável, plásticos ecológicos, sacolas recicláveis, enfim, produtos "verdes", que são oferecidos como possibilidade de consumir "de outra forma". A ecologia emerge, depois de tanto catastrofismo, como novo - e muito atrativo - mercado.

Outra dimensão da sensibilidade ecológica, expressa por movimentos espiritualistas, é "a busca de laços entre a pessoa e o planeta", ou seja, a formação de uma "consciência planetária" (Alphandéry, Bitoun, Dupont, 1992, p. 43). A natureza e o cosmos, para a humanidade atual, vivendo sufocada em sociedades massificadas e privada de qualquer transcendência espiritual, podem constituir fontes de enraizamento, de ruptura com uma vida social superorganizada e de reencantamento do mundo. A natureza passa a ser ressignificada no sentido de uma alternativa para trazer sentido e felicidade à humanidade.

Esse processo de popularização da ecologia e das ameaças que pairam sobre a humanidade e o planeta como um todo, se, por um lado, trouxe uma maior conscientização, por meio da educação ambiental, por outro, para o sociólogo Agripa Alexandre (2003), levou, em sentido contrário, à banalização da problemática socioambiental e à perda de radicalidade do movimento ambientalista, na medida em que o ambiente passou a ser fator importante para impulsionar o lucro de empresas, a publicidade, as demandas da mídia etc.

Estaríamos diante de um impasse, ao que parece. Como veremos a seguir, vários autores têm refletido sobre essa questão, oferecendo caminhos por meio de éticas ambientais que possam transcender o antropocentrismo.

\section{A saída por meio de um pensamento ético-ecológico}

Depois de uma extensa tradição de pensamento sobre as relações entre humanos e natureza, pelo menos desde o século XVIII, se adotarmos a ideia de Worster (2011), tomando Gilbert White e Linnaeus como marcos, 
chegaremos ao século XXI numa realidade de crise ambiental planetária. Como entender esse fracasso, mesmo com tão extensa reflexão sobre o tema?

Sem pretender responder a tão grave questionamento, nos limitamos a trazer alguns apontamentos para reflexão. Nem todas as lutas foram derrotadas; os ambientalistas tiveram suas vitórias, principalmente na forma de legislações e órgãos de regulação ambiental em muitos países. Empresas passaram a se preocupar em incluir parâmetros de controle ambiental em seus produtos - algo que pode ser alvo também de críticas, como vimos.

Para autores como Frijof Capra, Warwick Fox, Michel Serres, Edgar Morin, entre outros, no entanto, não bastam órgãos estatais, leis, ou marketing verde para tentar resolver a crise. Seria preciso uma mudança de postura da humanidade perante os elementos naturais; em outras palavras, a adoção de uma ética não antropocêntrica, que considerasse os direitos de todos os seres vivos, e não apenas os direitos humanos.

Essa ideia não é nova. Entre os principais defensores de uma "nova ética" entre humanos e natureza, de caráter biocêntrico, durante o século XX, podemos citar Albert Schweitzer, com sua "ética da reverência pela vida"; a "ética da Terra" de Aldo Leopold, já mencionada; Hans Jonas e a "ética da responsabilidade"; Arne Naess e a "ecologia profunda"12; a "hipótese Gaia", de James Lovelock e Lynn Margulis.

$\mathrm{Na}$ esteira desses pensadores, o sociólogo Edgar Morin defende a necessidade de um "pensamento ecológico". Através das descobertas científicas recentes, o dogma da separação entre os humanos e o mundo natural está sendo superado. Isso está levando à necessidade de um novo lugar para a humanidade, em relação à natureza, não mais insular, mas sim peninsular. É preciso que seja construída uma nova solidariedade e consciência de que a relação tem que ser de mão-dupla: "a natureza deve

${ }^{12}$ A ecologia profunda (deep, biocêntrica) foi proposta pelo filósofo norueguês Arne Naess, em artigo de 1973, que consistia essencialmente em sistematizá-la a partir de uma série de sete princípios caracterizadores, em contraponto à ecologia rasa (shallow, antropocêntrica). Naess continuou desenvolvendo suas ideias e a ecologia profunda se tornou uma das correntes mais influentes da ética ambiental contemporânea. 
ser dirigida pelo homem, mas este, por sua vez, deve ser dirigido pela natureza" (Morin, 1997, p. 61-62).

Dessa forma, seria possível superar o paradigma cartesiano - da disjunção entre sujeito/espírito e ciência/matéria - que legitimou o sonho de dominação dos humanos sobre a natureza, através da técnica. Em seu lugar, Morin propõe um novo paradigma, o da "auto-eco-organização", embasado no "pensamento complexo". O paradigma da auto-eco-organização "consiste em dizer que toda entidade auto-organizadora tem necessidade não somente de uma energia exterior a si própria, mas também, e sobretudo, de uma organização que Ihe seja exterior" (Morin, 1997, p. 63-64). Esse paradigma rejeita a disjunção humanidade-natureza e também a redução dos humanos à natureza. É uma revolução do pensamento: "todos os fenômenos que parecem interligados e sem conexões devem ser, a partir de agora, considerados independentes e autônomos e dependentes e conexos com todos os outros fenômenos que os cercam" (Morin, 1997, p. 65).

Para Morin, com ações ecologizadas e pensamento complexo, seria possível reverter a ameaça criada pela própria humanidade, a lógica da máquina, que baseou todo o processo de desenvolvimento até então. Processos técnicos que resolvem os problemas podem ser inventados, sem recorrer a catástrofes, o que consolidaria uma nova ética, baseada na lógica da regulação, não da destruição.

Como afirmou o ambientalista brasileiro José Lutzenberger, não é preciso descartar a tecnologia; ao contrário, a partir de uma visão sistêmica, ecológica, muito mais interessante é promover o elo entre tecnologia e ecologia. Para Lutzenberger (1983, p. 74), "na mesma proporção que abandonarmos a megatecnologia pelas tecnologias brandas, diminuirá o nosso impacto ambiental, aumentará nossa qualidade de vida e aumentarão as chances para nossos filhos".

Além da ecologia da ação, Morin (1997, p. 76) propõe uma ecologia das ideias: "devemos civilizar o mundo das ideias, porque mantemos hoje uma relação bárbara com nossas ideias, nossas ideias são bárbaras, e nós somos seus escravos, sem nem mesmo compreender que fomos 
nós mesmos que as geramos". Se adotasse a ecologização das ideias, a humanidade poderia compreender que não há nada de certo, de absoluto, qualquer que seja sua crença. Em especial, se pudesse duvidar de sua fé cega no desenvolvimento, na ciência e tecnologia, a humanidade poderia começar a mudar suas ideias. A partir disso, poderia haver uma mudança no comportamento humano em relação à natureza. No entanto, no contexto atual de expansão agressiva do sistema capitalista, cabe questionar se uma mudança ética, mesmo que profunda, seria suficiente.

Seria preciso, para a própria sobrevivência humana que acontecesse a mudança da lógica de pensamento da máquina escravizante do capitalismo para a lógica ecológica, que considera as inter-relações entre seres/coisas humanas e não humanas. Em suma, para Morin e outros autores que defendem a saída pela ética, a "cura" da humanidade levaria à "cura" da Terra.

\section{Considerações finais}

Aqui, busquei realizar uma síntese sobre importantes conceitos que permeiam a historicidade das representações sobre as relações entre humanos e natureza. Não tracei diferenças absolutas entre o ambientalismo e a sensibilidade ecológica, mas sim tentei caracterizá-los melhor e refletir sobre suas implicações, recorrendo a um diálogo multidisciplinar entre autores das Ciências Sociais. Digo isso, porque vários elementos da sensibilidade ecológica são apropriados pelos grupos ambientalistas, de acordo com as demandas das lutas com que se envolvem. O contrário nem sempre necessariamente acontece; alguém pode ter uma sensibilidade ecológica desenvolvida, sem estar engajado em uma entidade ambientalista.

Mais viável do que encontrar respostas de solução à crise ambiental é levantar questões e elementos para o debate. Porém, diante do exposto, parece-me, não é possível abrir mão da reflexão sobre ética e ambiente; é preciso enfrentá-la, em toda sua complexidade.

A questão ética é a dimensão central da sensibilidade humana em relação à natureza. Segundo Nash (1989), o "círculo da ética" foi se 
alargando com o tempo, do indivíduo ao universo. As questões éticas se estendem às condições de sobrevivência da biodiversidade, ao lugar do ser humano na natureza, à responsabilidade para com as gerações futuras, à distribuição de riqueza e bem-estar da humanidade, aos direitos dos outros "seres da natureza".

$\mathrm{O}$ artigo de White culpa o cristianismo, como a religião mais antropocêntrica que já existiu; no entanto Raynaut argumentou, de forma muito coerente, que houve outros fatores envolvidos, e que nem sempre os humanos adotaram uma postura de centralidade em relação à natureza. Diferentes visões de mundo, muitas vezes coexistentes no mesmo período histórico, orientaram variadas posturas em relação aos elementos naturais. A religião judaico-cristã foi um dos elementos que contribuíram para a ética dominante atual, porém não o único.

Alphandéry, Bitoun e Dupont elaboraram uma interessante análise dos elementos que compõem a sensibilidade ecológica, a partir dos anos 1970, quando a ecologia começou a tornar-se um dos discursos dominantes. Começando como profecia da ameaça iminente, calcada no medo, a ecologia chegou a questionar os pilares do sistema capitalista, especialmente seu principal dogma, o do crescimento sem limites, e parecia ser a saída para uma humanidade sem moral, sem rumo e sem Deus. No entanto, a partir dos anos 1980, estado e empresas perceberam as vantagens de se apropriar desse discurso. Surgiu o conceito de "desenvolvimento sustentável", em reação às propostas que apontavam o fim do crescimento econômico exponencial como única solução para a crise ambiental. Afirmando que conciliar crescimento e proteção à natureza era possível, desenvolvimento sustentável se tornou o discurso dominante, a partir dos anos 1990 e ainda no início do século XXI.

A ecologia se transformou numa moda muito lucrativa. Tudo que é verde - ou que a propaganda anuncia como verde - vende muito bem, de produtos recicláveis até turismo ecológico. Passada a etapa do medo apocalíptico, a ecologia tornou-se o grande mercado para o capitalismo neste século. A chamada economia verde é a grande "cartada" desse 
sistema-camaleão. Quando parecia moribundo, depois de tantas crises, o capitalismo encontra um meio de renovar-se, vestindo a roupa verde da sustentabilidade. Com isso, talvez almeje uma redenção, uma imagem menos agressiva. No entanto, o que é certo é que as grandes corporações, estados e elites políticas continuam lucrando muito. E, o melhor de tudo, para eles, é que não precisam mexer uma vírgula na lógica de funcionamento do sistema: a necessidade de crescimento econômico ilimitado. Já a natureza continua sendo representada como "recursos naturais", explorada, e de forma ainda mais intensa ${ }^{13}$. Por isso, o discurso quantificador, apontado por Alphandéry, Bitoun e Dupont, segue dominante - e revigorado. Mais ainda, a ética dominante permanece antropocêntrica.

A contribuição de McCormick é importante na pesquisa dos primeiros grupos protecionistas no mundo anglo-saxão. No entanto, sua visão extremamente otimista (pelo menos no texto citado aqui) não lhe permitiu perceber que a revolução ambientalista não foi tão revolucionária assim, como apontamos acima. Por outro lado, é preciso considerar que o ambientalismo moderno surgiu em meio a um contexto de medo da destruição do planeta; eram tantas as ameaças, que um movimento de cunho global não poderia ser evitado.

Muitos autores defenderam que somente a adoção de uma nova ética, capaz de superar o antropocentrismo e de guiar ações e ideias mais ecológicas, poderia, talvez, resolver o impasse humanos-natureza, superando-o. Morin (1997, p. 62) afirma que o pensamento complexo, ou pensamento ecológico, pode levar a essa nova ética; a humanidade se tornaria "pastor[a] da vida, abandonando seu sonho de dominação". É o que Junges (2010) chama de "ética do cuidado". O pensamento ecologizado, baseado na noção de humano como pastor, cuidador de Gaia, poderia superar a dicotomia antropocentrismo/biocentrismo. Seria uma ética embasada na lógica da regulação, não do massacre (Morin, 1997, p. 69).

${ }^{13}$ Em reportagem da revista National Geographic Brasil sobre economia verde, consta a seguinte chamada: "O camarão que vira remédio. A bromélia que vira autopeça. O peixe que vira roupa". Estes e outros exemplos são citados como modelos a serem seguidos, aliando ciência e empreendedorismo, para conciliar produção e biodiversidade (John, 2012). 
A representação predominante, de disjunção entre humanidade e natureza, nem sempre existiu - ela foi construída historicamente e hoje serve de alicerce para o sistema econômico mundial, que se expande sem parar, calcado na perversa demolição das bases da vida. Compreendendo os elementos que construíram essa representação e suas implicações para a sensibilidade ecológica e para o ambientalismo, chega-se à importância da ética. Discutir ética e ambiente se faz necessário, pois, se vimos que a atual representação nem sempre existiu, é através da continuidade desse fecundo debate que novas representações podem surgir, quem sabe, capazes de romper com a disjunção. Mas essa já é outra história.

Elenita Malta Pereira é Doutora em História e Professora no Departamento de História da Universidade Federal de Santa Catarina (UFSC). ORCID ID: https://orcid.org/0000-00019835-391X.

ఏ elenitamalta@gmail.com

\section{Referências}

1. ACOT, Pascal. História da ecologia. Rio de Janeiro: Editora Campus, 1990.

2. ALEXANDRE, Agripa. A perda da radicalidade do movimento ambientalista brasileiro. Uma nova contribuição à crítica do movimento. Ambiente \& Educação, Rio Grande, v. 8, n. 1, p. 73-94, 2003.

3. ALMEIDA, Jalcione; PREMEBIDA, Adriano. Histórico, relevância e explorações ontológicas da questão ambiental. Sociologias, Porto Alegre, v. 16, n. 35, jan/abr 2014, p. 14-33.

4. ALPHANDÉRY, Pierre; BITOUN, Pierre; DUPONT, Yves. O equívoco ecológico: riscos políticos. São Paulo: Brasiliense, 1992.

5. ARRUDA, Gilmar; SILVA, Aparecida Leite da; BIASETTO, Eliane Aparecida. Paisagens do medo: a expansão do ideário ecologista na cidade de Londrina- PR. Espaço Plural, Marechal Cândido Rondon, v. 12, n. 25, p. 49-62, 2o semestre 2011.

6. BONES, Elmar; HASSE, Geraldo. Pioneiros da ecologia: breve história do movimento ambientalista no Rio Grande do Sul. Porto Alegre: Já Editores, 2002.

7. BUBLITZ, Juliana. Entre tradição e modernidade: dilema do desenvolvimento no Brasil. Dissertação de Mestrado. Programa de Pós-Graduação em Desenvolvimento Regional da Universidade de Santa Cruz do Sul, 2006. 
8. CARSON, Rachel. Primavera silenciosa. São Paulo: Melhoramentos, 1964.

9. DEAN, Warren. A ferro e fogo. A história e a devastação da Mata Atlântica brasileira. São Paulo: Companhia das Letras, 1997.

10. DORST, Jean. Antes que a natureza morra. São Paulo: Editora da USP, 1973.

11. DRUMMOND, José Augusto. A história ambiental: temas, fontes e linhas de pesquisa. Estudos Históricos, v. 4, n. 8, p. 177-97, 1991.

12. DUARTE, Regina Horta. A biologia militante: o Museu Nacional, especialização científica, divulgação do conhecimento e práticas políticas no Brasil - 1926-1945. Belo Horizonte: Editora da UFMG, 2010.

13. DUMONT, René. A utopia ou a morte. São Paulo: Círculo do Livro, 1973.

14. DUMONT, René. O crescimento da fome. Lisboa: Editora Vega, 1974.

15. FALK, Richard. Morte e sobrevivência da Terra. Rio de Janeiro: Artenova, 1972.

16. FRANCO, José Luiz de Andrade; DRUMMOND, José Augusto. Proteção à natureza e identidade nacional no Brasil: anos 1920-1940. Rio de Janeiro: Fiocruz, 2009.

17. GOLDSMITH, Edward et al. A blueprint for survival. The Ecologist. v. 2, n. 1, p. 23-43, 1972. Disponível em: <https://www.resurgence.org/magazine/ ecologist/issues1970-1979.html>.

18. ILLICH, Ivan. Energia y equidad. Desempleo creador. Madrid: Joaquim Mortiz/Planeta, 1985.

19. JATOBÁ, Sérgio; CIDADE, Lúcia; VARGAS, Glória. Ecologismo, ambientalismo e ecologia política: diferentes visões da sustentabilidade e do território. Sociedade e Estado, Brasília, v. 24, n. 1, p. 47-87, jan./abr. 2009.

20. JOHN, Liana. Economia verde. National Geographic Brasil, São Paulo, n. 147, jun. 2012.

21. JONAS, Hans. O princípio responsabilidade. Rio de Janeiro: Contraponto/ PUC-Rio, 2006.

22. JUNGES, José Roque. (Bio)ética ambiental. São Leopoldo: Editora da Unisinos, 2010.

23. LENZI, Cristiano Luís. Sociologia ambiental: risco e sustentabilidade na modernidade. Bauru: EDUSC, 2006.

24. LEOPOLD, Aldo. Pensar como uma montanha (A Sand County almanac). Águas Santas, Portugal: Edições Sempre-em-pé, 2008.

25. LUTZENBERGER, José. Fim do Futuro? Manifesto ecológico brasileiro. 3. ed. Porto Alegre: Movimento/Editora da UFRGS, 1983. 
26. MCCORMICK, John. Rumo ao paraíso: a história dos movimentos ambientalistas. Rio de Janeiro: Relume-Dumará, 1992.

27. McNEILL, John. R. Something new under the sun: an environmental history of the twentieth-century world. New York, London: W. W. Norton \& Company, Inc., 2000.

28. MEADOWS, Donella H. et al. Limites do crescimento. São Paulo: Editora Perspectiva, 1972.

29. MORIN, Edgar. Por um pensamento ecologizado. In: CASTRO, Edna; PINTON, Françoise. Faces do trópico úmido. Belém: UFPA/NAEA, 1997.

30. NASH, Roderick. The rights of nature: a history of environmental ethics. Madison, Wisconsin: The University of Wisconsin Press, 1989.

31. OLIVEIRA, Wilson José Ferreira. "Paixão pela natureza", atuação profissional e participação na defesa de causas ambientais no Rio Grande do Sul entre 1970 e início dos anos 2000. Tese de Doutorado. PPG em Antropologia Social UFRGS. Porto Alegre, 2005.

32. PÁDUA, José Augusto. Um sopro de destruição. Pensamento político e crítica ambiental no Brasil escravista (1786-1888). Rio de Janeiro: Jorge Zahar, 2002.

33. PÁDUA, José Augusto. Herança romântica e ecologismo contemporâneo. Existe um vínculo histórico? Varia História, Belo Horizonte, v. 21, n. 33, p. 58-75, jan. 2005.

34. PÁDUA, José Augusto. As bases teóricas da história ambiental. Estudos Avançados, São Paulo, v. 24, n. 68, 2010.

35. PEREIRA, Elenita M. Roessler: o homem que amava a natureza. São Leopoldo: Oikos, 2013.

36. PEREIRA, Elenita M. Movimentos ambientalistas no Rio Grande do Sul (Décadas 1970-80). Oficina do Historiador, Porto Alegre, v. 11, n. 1, jan./jun. 2018.

37. PEREIRA, Elenita M. Naturismo, ética e ecologia na proteção à natureza: a fundação da AGAPAN (1971). In: FRANCO, José Luiz A. et al. (Orgs.). História ambiental. Vol. 3. Rio de Janeiro: Garamond, 2019. No prelo.

38. PEPPER, David. Ambientalismo moderno. Lisboa: Instituto Piaget, 1996.

39. PORTO-GONÇALVES, Carlos Walter. Ecologia e capital: quando a teoria não esquece o mundo. Revista Iberoamericana de Economia Ecológica, v. 12, p. 85-90, 2009.

40. RAYNAUT, Claude. As relações ser humano/natureza: arqueologia social de uma ruptura. Conferência ministrada no Curso de Doutorado em Meio Ambiente e Desenvolvimento/UFPR, mar. 2006, não publicado.

41. RÜCKERT, Fabiano. O ambientalismo em três escalas de análise. Cadernos IHU, São Leopoldo, v. 13, n. 51, 2015. 
42. THOMAS, Keith. O homem e o mundo natural: mudanças de atitude em relação às plantas e aos animais, 1500-1800. São Paulo: Cia das Letras, 1988.

43. WHITE, Lynn. Raízes históricas da nossa crise ecológica. Tradução de Roberto A. Dantes. São Paulo, Pensamento Ecológico, n. 13, jul. 1981.

44. WORSTER, Donald. Para fazer história ambiental. Estudos Históricos, Rio de Janeiro, v. 4, n. 8, p. 198-215, 1991.

45. WORSTER, Donald. Transformações da Terra: para uma perspectiva agroecológica na história. Ambiente \& Sociedade, Campinas, v. 5, n. 2, p. 23-44, 2003.

46. WORSTER, Donald. Nature's economy: a history of ecological ideas. Second Edition. Cambridge: Cambridge University Press, 2011. 